\title{
RESEARCHES ON SOOT FILTRATION PROCESS BY COMPARING SIMULATION AND EXPERIMENTAL TESTS
}

\section{Bogdan Manolin JURCHIS}

Technical University of Cluj-Napoca, Romania

e-mail: bogdan.jurchis@auto.utcluj.ro

\begin{abstract}
In this paper, the main objective of using numerical simulation was to highlight and analyse details that are very difficult to highlight through experimental tests. The development of the simulation model was also done for predictive purposes. In other words, after validation of the model, it can be used to estimate the filter load in other conditions than the experimental ones, respectively to evaluate how the particulate filter affects the operation of the internal combustion engine. In order to achieve the desired result, the creation of the model was done in two stages, the first stage was the creation of a model containing all the components of the engine, except the particle filter in order to identify the parameters of the combustion process and pollutant emissions - model validated on the basis of the indicated pressure curves, and the second stage was to complete the initial model with a particle filter and validate it from the point of view of the pressure drop, respectively of the engine performance, the aim was to obtain a trend, respectively values similar to the experimental ones.
\end{abstract}

KEYWORDS: simulation model, combustion engine, pollutant emissions

\section{Introduction}

The soot particles resulting from the combustion process are microscopic carbon particles. Based on the analysis with an electron microscope, it is found that the soot particles are arranged randomly and that they have a certain degree of overlap. The size of the primary particles and their degree of overlap depends on quantity of fuel injected and also about the initial conditions regarding combustion process.
Approximately $0.5 \%$ of the mass of fuel is emitted as very small solid particulates matter with a diameter of about $0.1 \mu \mathrm{m}$ [1]. Soot is produced during pyrolysis at high temperatures [2, 3]. Figure 1 shows a micrograph of the Diesel soot in which particles can be observed, consisting of spherical agglomerates. Due to the extremely small size of the solid particles, it was necessary to create a simulation model for a better highlight the amount of soot deposited in the particle filter.

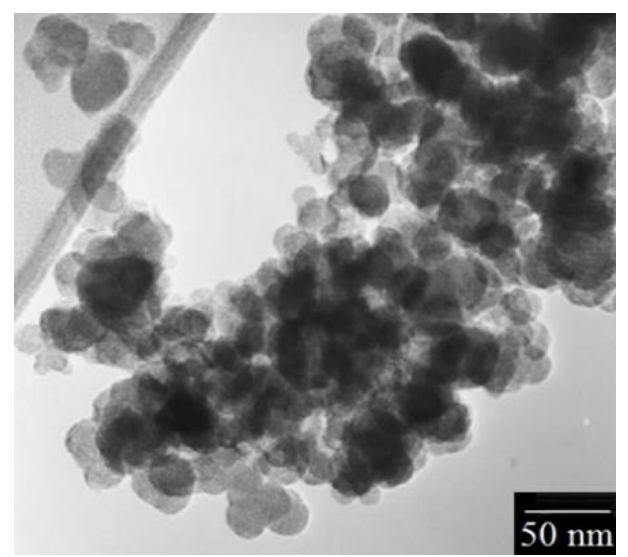

Fig. 1. Soot micrograph consisting of groups of spherical particles [4] 
The DPF model implemented in BOOST combines in a single global solution detailed and pragmatic approaches for the flow of filtration and regeneration. It allows the user to take into account the ash or not, to choose the structure of his cups and also to use different materials for the particle filter on which the simulations are performed. For the simulation model created in this doctoral dissertation, a model of square cell particle filters was used in which a pair of inlet and outlet channels, channels loaded with soot and ash are presented. In the AVL BOOST program, different geometric shapes of the input channel were studied, namely: square, hexagonal, octagonal, rectangular. The soot is divided into two distinct layers: a deep layer and an outer layer, therefore the model made distinguishes between the soot located in the porous wall of the filter and the soot formed at the surface of the channel. An increased soot burning rate can be simulated in the deep layer by applying catalytically supported regeneration mechanisms. The presence of a layer of ash causes a pressure drop because it induces an additional flow resistance and a front flow surface [5]. In models where soot is described by a depth layer and a filtration layer, the ash layer can be understood as a barrier between the two layers of soot. Thus, soot cannot be stored in the deep layer as long as a layer of ash is present. The existence of an ash plug leads to a reduced filtration efficiency and therefore to an additional pressure drop. The actual filter length is also reduced by the size of the ash accumulations in the filter channels. A time finding for the whole filtration process based on the simulations, especially for the flow rates and for the increase of the soot layer, revealed that the gas phase processes can be assumed to be constant. The thickness of the soot layer, from the depth filtration layer of a channel with 4 filter walls, the height of the soot layer and the thickness of the ash layer $\delta_{a c}$ were calculated with the relation [6]:

$$
\delta_{s d}=\frac{m_{s d} \cdot A_{\text {front }}}{n_{1} * \rho_{s d}} \cdot \frac{1}{n_{f w} d_{1}}
$$

where: $\mathrm{m}_{\mathrm{sd}}$ - represents the soot loading in the deep layer; $A_{\text {front }}$ - the front surface of the filter; $n_{1}$ number of input channels; $\rho_{\mathrm{sd}}$ - soot density in the deep layer; $\mathrm{n}_{\mathrm{fw}}$ - number of active filtered walls; $\mathrm{d}_{1}$ diameter of the inlet channel.

\section{Materials and methods}

The simulation model created in AVL BOOST is based on the experimental engine AVL-5402 used in experimental research. The technical data provided by the manufacturer of the engine was used to create the simulation model. The model created in AVL BOOST fully complied with the parameters and related connections that were on the experimental model (Fig. 2). The simulation process consisted of the creation in the first phase of the single-cylinder engine model used in the experimental research in order to be able to extract the data regarding the gas flow resulting from the combustion process. The second phase consisted of creating and adapting a particle filter on the exhaust system defining each parameter separately. The "DPF" particle filter was modeled to highlight the correlation between the quantity of soot produced, the model of the channels, the channel structure, and the blend of fuel used in the research process.

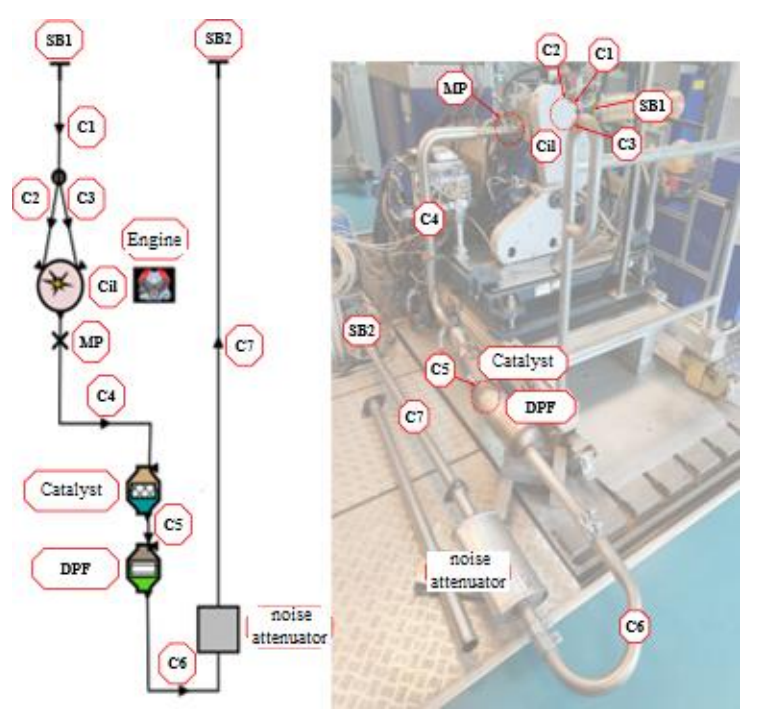

Fig. 2. The simulation model created and the experimental engine equipped with DPF 

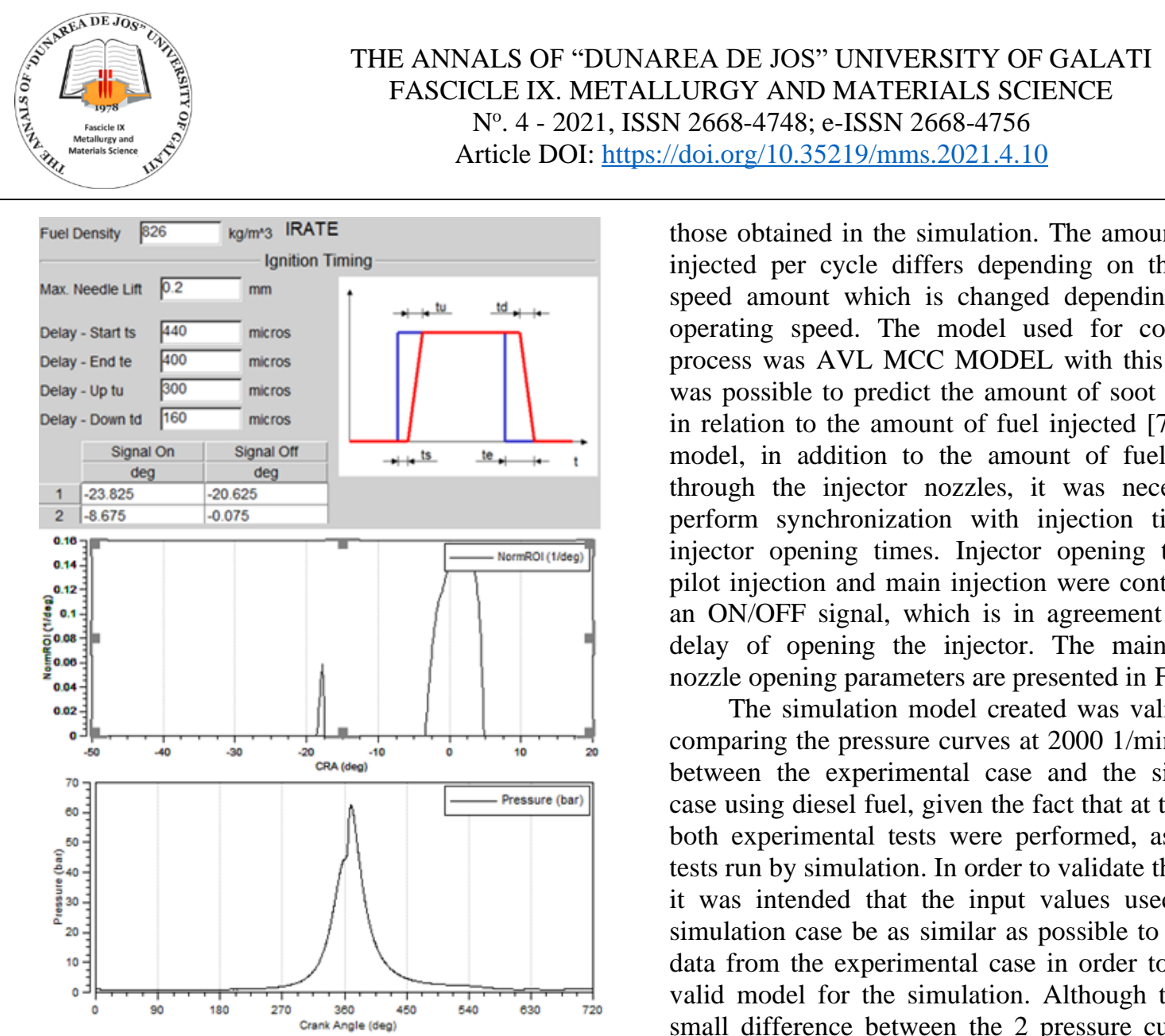

those obtained in the simulation. The amount of fuel injected per cycle differs depending on the engine speed amount which is changed depending on the operating speed. The model used for combustion process was AVL MCC MODEL with this model it was possible to predict the amount of soot produced in relation to the amount of fuel injected [7]. In this model, in addition to the amount of fuel injected through the injector nozzles, it was necessary to perform synchronization with injection times and injector opening times. Injector opening times for pilot injection and main injection were controlled by an ON/OFF signal, which is in agreement with the delay of opening the injector. The main injector nozzle opening parameters are presented in Figure 3

The simulation model created was validated by comparing the pressure curves at $20001 /$ min (Fig. 4) between the experimental case and the simulation case using diesel fuel, given the fact that at this speed both experimental tests were performed, as well as tests run by simulation. In order to validate the model, it was intended that the input values used for the simulation case be as similar as possible to the input data from the experimental case in order to create a valid model for the simulation. Although there is a small difference between the 2 pressure curves, the model was considered valid given that these differences are below $0.5 \%$ so we have an almost complete overlap of the pressure curves.

The comparison of the simulation results was performed by overlapping the experimental data with

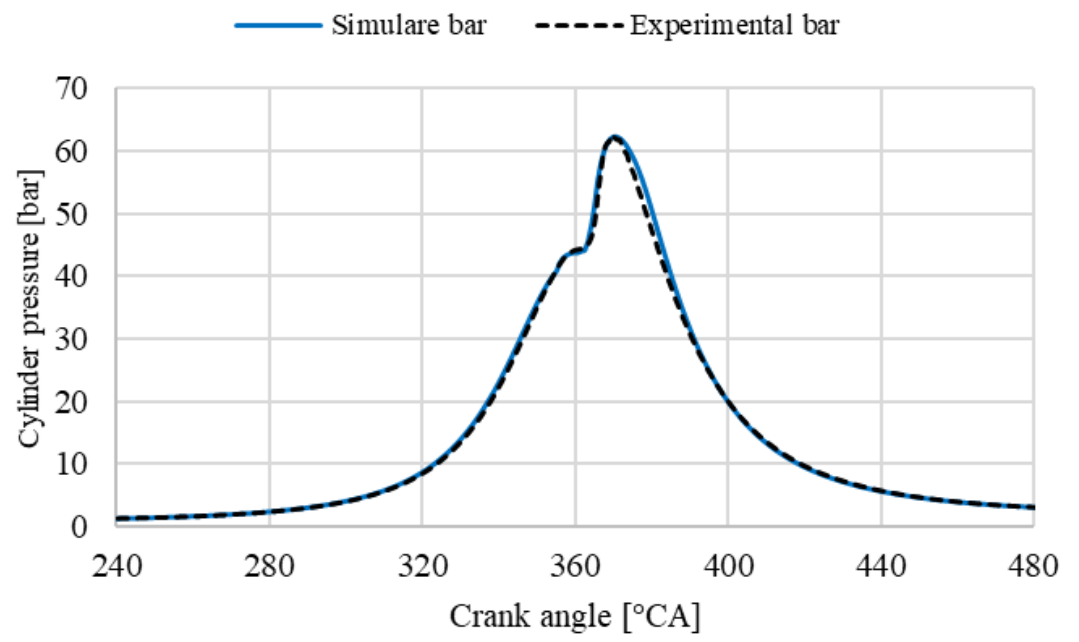

Fig. 4. Comparison of pressure curves at 2000 [1/min]

\section{Results and discussion}

In order to create a model capable of simulating the exhaust gas after-treatment process (Fig. 5) the boundary conditions for the inlet and outlet channels of the particulate filter system had to be defined. At the inlet, the mass gas flow obtained after simulating the combustion process was specified the pressure and boundary conditions for the exit of the filter were specified, the conditions of adiabatic gasodynamic resistance had to be defined in order not to change the thermal gradient or the species of the gas mass fractions. The following data were required for modeling the inlet to the exhaust after-treatment 
system: definition of the main dimensions of the DPF (monolith dimensions and monolith volume), mass gas flow, temperature, molar fraction of the exhaust gas and the solid mass fraction (Fig. 6). This simulation was followed by pressure drops depending on the degree of filter loading.

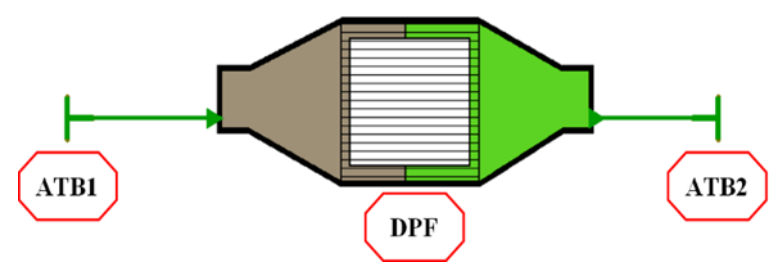

Fig. 5. The DPF model created in AVL BOOST

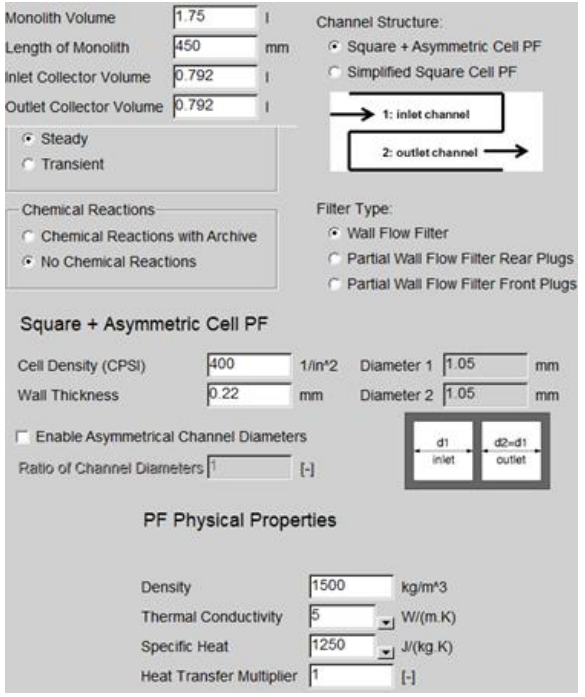

Fig. 6. Parameter used to create the simulation model

The discretization of the model was done by assigning the correction factor "Grid Shape Factor = $1 "$ and by dividing the model axially into 100 measurement points, points that are equal as can be seen in Figure 7. These points determined the number of cells that entered the DPF simulation calculation. The physical properties of the particle filter that were introduced to create the model were necessary to be able to observe its thermal behavior, especially the heat transfer that takes place between the walls of the filter. All the physical properties of the filter, its specific density, and heat have been introduced, so that the heat transfer that takes place between the walls of the particle filter can be calculated.

The simulation aimed to highlight, based on the model created and validated in AVL Boost, the total mass of soot emitted in 5 hours of operation for the 3 fuels analysed (D100 - means pure diesel, B20 means pure diesel with $20 \%$ of biodiesel in blend and B30 means pure diesel with $30 \%$ of biodiesel in blend). The pressure drops on the soot layer as shown in figure 8 was directly proportional to the total mass of soot obtained after 5 hours of operation. Thus, for D100, the largest pressure drop on the soot layer was found, namely 12.94 mbar, for B20 we had $8.71 \mathrm{mbar}$ and 6.07 mbar for B30. The simulation data confirm the experimental results, namely that $\mathrm{B} 30$ produced the lowest solid particulate emissions. Due to the limitations, it is very hard to measure exactly the amount of soot emitted, but by simulation it was possible to calculate the exact soot emission in [mg]. As shown in figure 9 the trend of soot emissions is directly proportional to the total pressure drop. Thus, for D100, a $25.12 \%$ increase in soot emissions compared to $\mathrm{B} 20$ was obtained, respectively by $47.5 \%$ compared to B30.
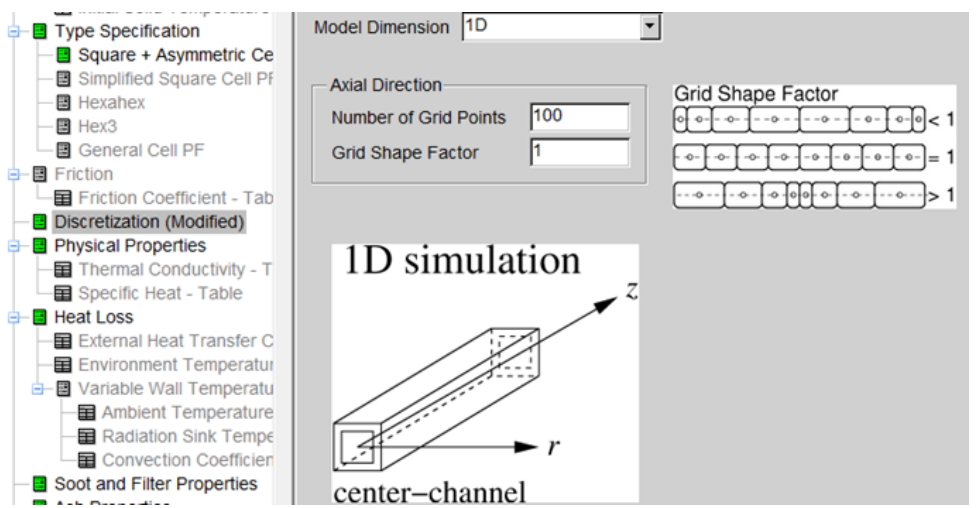

Fig. 7. Discretization of the particulate filter model 


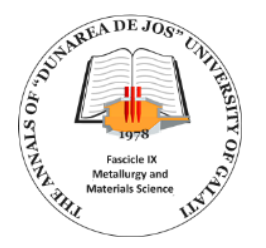

THE ANNALS OF “DUNAREA DE JOS” UNIVERSITY OF GALATI

FASCICLE IX. METALLURGY AND MATERIALS SCIENCE

No. 4 - 2021, ISSN 2668-4748; e-ISSN 2668-4756

Article DOI: $\underline{\text { https://doi.org/10.35219/mms.2021.4.10 }}$

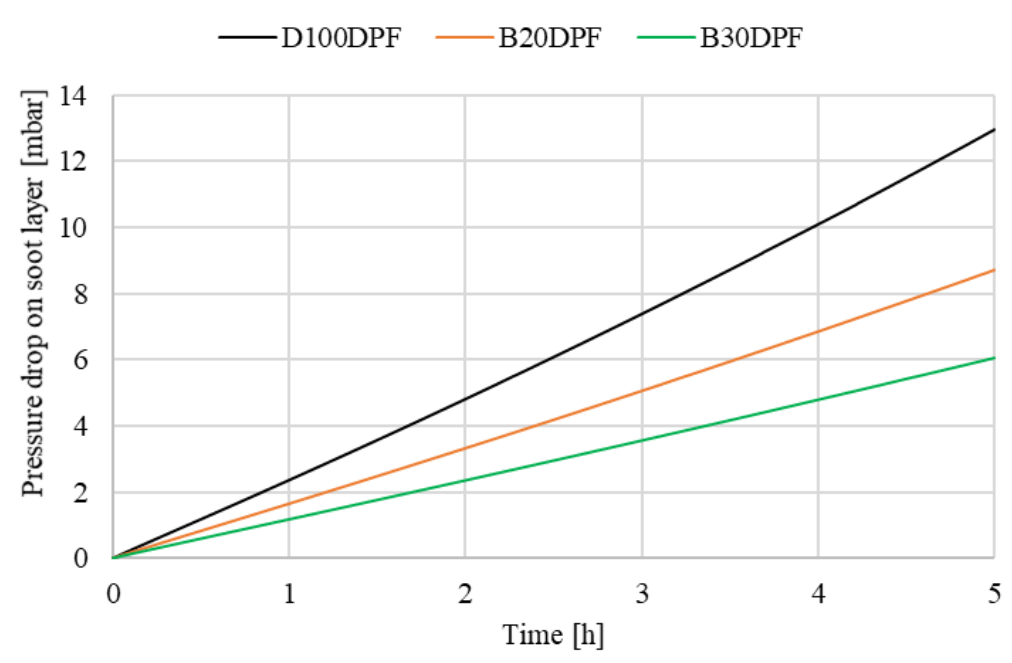

Fig. 8. Pressure drop for the cases studied by simulation

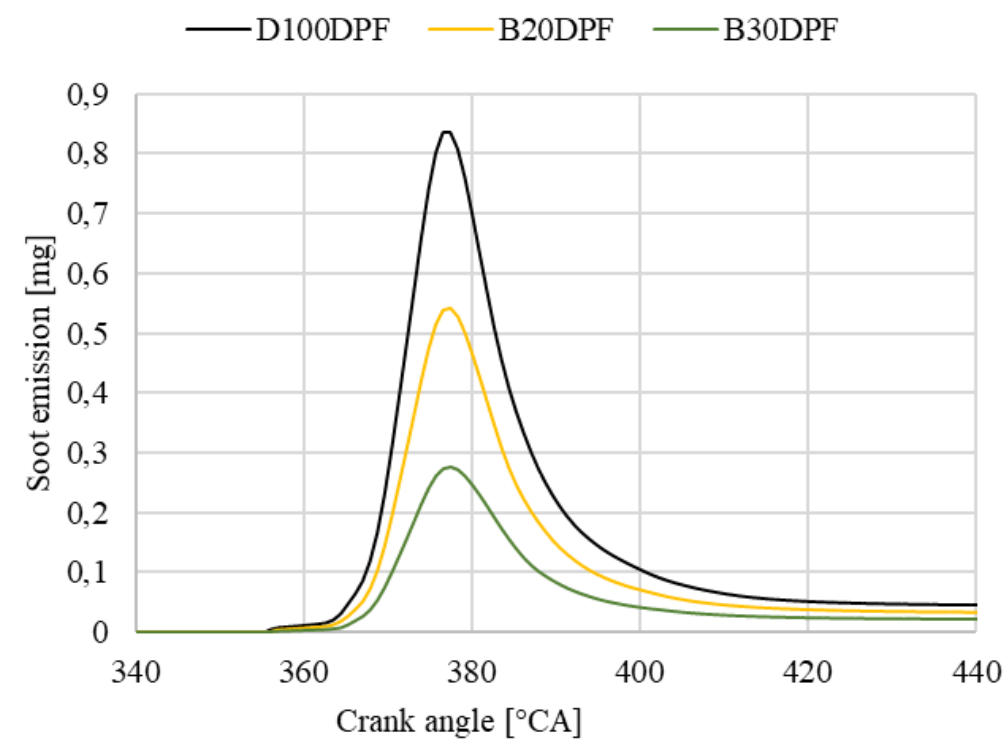

Fig. 9. Soot emission obtained by simulation B20_DPF; B30_DPF; Diesel_DPF

\section{Conclusions}

- The simulation model created in AVL Boost was validated by comparing the pressure curves. The overlap is almost perfect, and it can be concluded that the simulation model created is valid.

- The results obtained by simulation regarding the pressure drop were 12.94 mbar for D100DPF, $8.71 \mathrm{mbar}$ for B20DPF and $6.07 \mathrm{mbar}$ for B30DPF.

- The trend of soot emissions is directly proportional to the total pressure drop. Thus, for D100 there was an increase of $25.12 \%$ in soot emissions compared to B20, respectively by $47.5 \%$ compared to B30.

- The DPF model created by the simulation can be used for various future research using various fuels and using various injection strategies

\section{Acknowledgements}

The data presented in this paper were obtained from my $\mathrm{PhD}$ thesis "Studies and research on improving the operation of particulate filters in the use of various fuels" F-CA-39032/23.06.2021. I would like to thank AVL company for the support provided in this research.

\section{References}

[1]. Mathis U., Mohr M., Forss A.-M., Comprehensive particle characterization of modern gasoline and diesel passenger cars at low ambient temperatures, Atmospheric Environment, vol. 39, 2005.

[2]. Böhm H., Jander H., Tanke D., PAH growth and soot formation in the pyrolysis of acetylene and benzene at high 
THE ANNALS OF "DUNAREA DE JOS" UNIVERSITY OF GALATI

FASCICLE IX. METALLURGY AND MATERIALS SCIENCE

No. 4 - 2021, ISSN 2668-4748; e-ISSN 2668-4756

Article DOI: https://doi.org/10.35219/mms.2021.4.10

temperatures and pressures: Modeling and experiment, Symposium (International) on Combustion, vol. 27, 1998.

[3]. Ruiz M. P., de Villoria R. G., Millera A., Alzueta M. U., Bilbao R., Influence of the temperature on the properties of the soot formed from $\mathrm{C}_{2} \mathrm{H}_{2}$ pyrolysis, Chemical Engineering Journal, vol. $127,2007$.

[4]. Xi J., Zhong B.-J., Soot in Diesel Combustion Systems, Chemical Engineering \& Technology, vol. 29, 2006.
[5]. Awais M., Bhuiyan A. A., Recent advancements in impedance of fouling resistance and particulate depositions in heat exchangers, International Journal of Heat and Mass Transfer, vol. 141, 2019.

[6]. Engeljehringer K., AVL Emission Test Systems Light-Duty Application: Cars and LCV, 2013.

[7]. Jurchiş B., Nicolae B., Iclodean C., Burnete N., Study of emissions for a compression ignition engine fueled with a mix of DME and diesel, vol. 252. 2017. 